\title{
OтоLоgy
}

\section{Quality of life measurements for patients with chronic suppurative otitis media: Italian adaptation of "Chronic Ear Survey"}

\section{La misura della qualità della vita in pazienti con otite media suppurativa cronica: adattamento in italiano del "Chronic Ear Survey"}

\author{
G. RALLI', C. MILELLA' 1 , M. RALLI², M. FUSCONI', G. LA TORRE ${ }^{3}$ \\ ${ }^{1}$ Dipartimento Organi di Senso, Sapienza Università di Roma "La Sapienza"; ${ }^{2}$ Dipartimento di Scienze \\ Odontostomatologiche e Maxillo Facciali, Università di Roma "La Sapienza"; ${ }^{3}$ Dipartimento di Sanità Pubblica \\ e Malattie Infettive, Università di Roma "La Sapienza"
}

\section{SUMMARY}

The chronic ear survey (CES) is a sensitive and disease specific quality of life (QoL) measurement tool in patients with chronic suppurative otitis media (CSOM). It is a 13-item survey that evaluates the frequency, duration and severity of problems associated with this disease. It is composed of three subscales that describe activity restrictions, symptoms and medical resource utilisation. Based on patient's answers, it is possible to obtain a score resulting in a scale ranging from 0 to 100; the highest indicates the best health, while the lowest denotes poor health. The questionnaire was originally created in English. The aim of this study is to validate the CES questionnaire in Italian (CES-I). Translation was made following international guidelines. The application follows the stages of translation from English to Italian and linguistic adaptation, and grammatical and idiomatic equivalence review. The CES-I and the Short Form Health Survey 36 (SF-36) questionnaires were administered to 54 patients with CSOM. A cross-sectional design was used to examine the internal consistency (Cronbach's alpha) and concurrent validity (Pearson's product moment correlation). To confirm the external validity of CES-I, Pearson correlation coefficient, considering the total score and single subscales of CES and the 8 scales of the SF-36, was calculated. Cronbach's alpha coefficient for internal consistency was 0.737 . The intraclass correlation coefficient, measured through mixed effects, was 0.737 ( $95 \%$ CI: $0.600-0.835, \mathrm{p}<0.001)$ for average measures and 0.412 (95\%CI: $0.273-0.559, \mathrm{p}<0.001)$ for individual measures. According to our results, CES-I is a reliable tool for evaluation of QoL in patients with CSOM among the Italian-speaking population.

KEY WORDS: Quality of life $\bullet$ Chronic suppurative otitis media $\bullet$ Chronic ear survey $\bullet$ Validation $\bullet$ SF-36

\section{RIASSUNTO}

Il Chronic Ear Survey (CES) è una misura specifica della Qualità della Vita (QoL) nei pazienti affetti da Otite Media Suppurativa Cronica $(C S O M)$. È un questionario composto da 13 domande che indagano frequenza, durata e severità dei sintomi associati a questa malattia. Il CES genera tre sottoscale con rispettivo punteggio che riguardano limitazioni nelle attività fisiche e sociali, sintomi e trattamento medico. Attraverso le risposte ottenute dai pazienti è possibile ricavare un punteggio che va da 0 a 100; il punteggio più alto indica una QoL migliore, mentre quello più basso indica una QoL peggiore. Il questionario è stato creato in lingua inglese. Lo scopo del lavoro è di validare in lingua italiana il CES. La traduzione è stata condotta seguendo le linee guida internazionali. La versione italiana del CES (CES-I) è stata proposta a 54 pazienti con CSOM. Nello stesso tempo, è stato somministrato a tutti i pazienti anche il questionario SF-36. Un modello trasversale è stato usato per esaminare la consistenza interna (Cronbach alpha) e la validità esterna (coefficiente di Pearson). Per confermare la validità esterna del CES-I è stato poi analizzato il test di correlazione di Pearson considerando il punteggio totale, le singole sottoscale del CES e le 8 scale dello Short Form Health Survey (SF-36). Il coefficiente di Cronbach è stato pari a 0.737. Il coefficiente di correlazione interno ha dato un risultato pari a 0.737 (95\% CI: 0.600-0.835, $p<0.001$ ) di media e 0.412 (95\% CI: 0.237-0.559, $p<0.001$ ) per le singole misure. Sulla base dei nostri risultati il questionario CES-I è risultato essere concorde con l'originale in lingua inglese e può essere considerato uno strumento adeguato per valutare la Qualità della Vita nei pazienti con CSOM di lingua italiana.

PAROLE CHIAVE: Qualità della vita $\bullet$ Otite media suppurativa cronica $\bullet$ Chronic ear survey • Validazione $\bullet S F-36$

Acta Otorhinolaryngol Ital 2017;37:51-57

\section{Introduction}

Chronic suppurative otitis media (CSOM) is characterised by an evident and definite perforation of the tympanic membrane and by constant or intermittent middle ear inflammation often associated to a chronic or intermittent otorrhoea ${ }^{1}$
From a clinical point of view, the CSOM presents significant functional limitations of hearing. Other unpleasant symptoms include malodorous ear, fullness, ear pain, headaches, and vertigo ${ }^{2}$. Tinnitus, although a common symptom also associated to a variety of other conditions ${ }^{3}$ 
may be present. Although during the recent decades the incidence of CSOM has significantly decreased in developed countries ${ }^{4}$ thanks to improvements in housing, hygiene, and antibiotic use, it still represents a dangerous disease with severe complications such as cholesteatoma. Spontaneous healing is rare and the cure is possible only through a medical and surgical therapeutic strategy.

CSOM can severely impact quality of life (QoL) of patients. The concept of QoL emerged in the $1970 \mathrm{~s}$ as an important new outcome for healthcare ${ }^{5}$. The World Health Organization (WHO) defines the QoL as the individual's perception of his/her position in life, in the context of the culture and value system in which he/she is inserted and in relation to his/her goals, expectations, patterns and worries ${ }^{6}$.

The notion of health-related quality of life (HRQoL) has evolved since the 1980s as a subjective and multi-dimensional concept that includes domains related to physical, mental, emotional and social functioning. It goes beyond direct measures of population health, life expectancy, causes of death and focuses on the impact of health status on quality of life ${ }^{7}$.

The measurement of general HRQoL is usually performed using a questionnaire called the Short Form 36 Health Survey (SF-36) ${ }^{8}$. The SF-36 includes one multiitem scale that assesses eight different health concepts: 1 ) limitations in physical activities because of health problems; 2) limitations in social activities because of physical or emotional problems; 3) limitations in usual role activities because of physical health problems; 4) bodily pain; 5) general mental health (psychological distress and wellbeing); 6) limitations in usual role activities because of emotional problems; 7) vitality (energy and fatigue); and 8 ) general health perceptions ${ }^{9}$. The eight scales are scored individually and then combined, resulting in a score ranging from 0 to 100 ; the highest score indicates the best health, while the lowest denotes poor health. An Italian validated version of SF-36 is available since $2000{ }^{10}$.

It has been demonstrated that SF-36 is not very sensitive to assess the impact of a single disease on HRQoL; moreover, it does not focus on individual symptoms ot mirror the subjective experience of patients ${ }^{11}$.

In 2000, Wang and Nadol ${ }^{12}$ analysed results of the SF36 questionnaire in patients with CSOM vs. a control group of healthy subjects: although scores for several of the SF-36 subsections were lower in the CSOM group, no statistically significant differences were found between the CSOM and control groups. Moreover, postoperative SF-36 score did not change significantly compared to the preoperative score.

To overcome these difficulties for patients with CSOM, Nadol proposed and developed the chronic ear survey (CES) questionnaire ${ }^{13}$, a sensitive and disease-specific QoL measurement in patients with CSOM. CES is a 13-item survey that evaluates the frequency, duration and severity of problems associated with CSOM, by analysing the total score and 3 subscale scores (activity restrictions, symptoms and medical resource utilisation) that objectively evaluate overall CSOM patient discomfort and the effects of medical and surgical management. The final score ranges from 0 to 100; the highest score indicates the best health, while the lowest denotes poor health.

The CES score has the aim of calculating objective discomforts in patients and the effects of medical and surgical management of CSOM patients. To calculate the total score of the CES questionnaire, it is necessary to apply a definite value from 0 to 100 for every answer. The total values obtained from each section (Activity Restriction, Symptom and Medical Resource) are then divided by the number of the questions (i.e. in the Activity Restriction section the values obtained are added and divided by 3 ; in the Symptom section are divided by 7$)$. Total values for the three sections $(\mathrm{A}+\mathrm{S}+\mathrm{M})$ are summed and then divided by 3 , resulting in the final value of the questionnaire.

The questionnaire was originally written in English and has been translated and validated in Chinese and Korean ${ }^{14} 15$.

The term "validity" indicates the robustness and reliability of a survey, which is a real correspondence between the real world and research findings, and refers to how well a test measures what it is purported to measure ${ }^{16}$. It is essential, therefore, that the questionnaire actually measures what the researcher is intending to measure ${ }^{17}$. The validation process goes beyond simple translation, and a validated questionnaire gives the opportunity to collect and compare data from populations with different languages.

The CES questionnaire has been shown by Nadol et al. ${ }^{13}$ to be a valid, disease-specific health measure that can be used to evaluate adult patients with CSOM; however, this tool is not available in the Italian language and therefore cannot be used in the Italian speaking population.

The aim of this paper is to propose a translated version of the CES questionnaire in the Italian language (CES-I) following international guidelines and to assess its validity in an Italian sample of patients affected by unilateral or bilateral CSOM.

\section{Materials and methods}

The study was approved by the Ethics Committee of the "Sapienza" University. All patients signed specific informed consent forms.

\section{Translation and adaptation}

In the first phase of this study, the CES questionnaire was translated from English into Italian (CES-I). The process of translating the CES questionnaire followed international guidelines through a process of reviews and modifications ${ }^{18}$. Two expert otorhinolaryngologists and two 
Table I. Chronic Ear Survey (CES).

\section{Activity Restriction-Based Subscale}

A1 Because of your ear problem, you don't swim or shower without protecting your ear.

$\square$ definitely true $\square$ true $\square$ don't know $\square$ false $\square$ definitely false

A2 At the present time, how severe a limitation is the necessity to keep water out of your ears?

$\square$ very severe $\square$ severe $\square$ moderate $\square$ mild $\square$ very mild $\square$ none

A3 In the past 4 weeks, has your ear problem interfered with your social activities with friends, family, or groups?

$\square$ all of the time $\square$ most of the time $\square$ a good bit of the time $\square$ some of the time $\square$ a little of the time $\square$ none

Symptom Subscale
S1 $\quad$ Your hearing loss is:
S2 $\quad \square$ very severe $\square$ severe $\square$ moderate $\square$ mild $\quad \square$ very mild $\square$ none
Srainage from your ear is:
$\quad \square$ very severe $\square$ severe $\square$ moderate $\square$ mild $\square$ very mild $\square$ none
S3 $\quad$ Pain from your ear is:

S4 Odor from your ear is very bothersome to you and/or others:

$\square$ definitely true $\square$ true $\square$ don't know $\square$ false $\square$ definitely false

S5 The hearing loss in your affected ear bothers you:

$\square$ all of the time $\square$ most of the time $\square$ a good bit of the time $\square$ some of the time $\square$ a little of the time $\square$ none

S6 In the past 6 months, please estimate the frequency that your affected ear has drained:

$\square$ constantly $\square>5$ times, but not constantly $\square$ 3-4 times $\square$ 1-2 times $\square$ not at all

S7 The odor from your affected ear bothers you and/or others:

$\square$ all of the time $\square$ most of the time $\square$ a good bit of the time $\square$ some of the time $\square$ a little of the time $\square$ none

Medical Resource Utilisation Subscale

M1 In the past 6 months, how many separate times have you visited your physician, specifically about your ear problem?

$\square>6$ times $\square>5$ times, but not constantly $\quad$ 3-4 times $\quad$ 1-2 times $\square$ not at all

M2 In the past 6 months, how many separate times have you used oral antibiotics to treat your ear infection?

$\square>6$ times $\square>5$ times, but not constantly $\square$ 3-4 times $\square$ 1-2 times $\square$ not at all

M3 In the past 6 months, how many separate times have ear drops been necessary to treat your ear condition?

$\square>6$ times $\square>5$ times, but not constantly $\square$ 3-4 times $\square$ 1-2 times $\square$ not at all

Table II. Chronic Ear Survey (CES) score calculation.

\begin{tabular}{ll} 
Activity & Restriction: $(\mathrm{A} 1+\mathrm{A} 2+\mathrm{A} 3) / 3=\mathrm{A}$ \\
A1 & $0-25-50-75-100$ \\
A2 & $0-20-40-60-80-100$ \\
A3 & $0-20-40-60-80-100$ \\
Symptoms: $(\mathrm{S} 1+\mathrm{S} 2+\mathrm{S} 3+\mathrm{S} 4+\mathrm{S} 5+\mathrm{S} 6+\mathrm{S} 7) / 7=\mathrm{S}$ \\
S1 & $0-20-40-60-80-100$ \\
S2 & $0-20-40-60-80-100$ \\
S3 & $0-20-40-60-80-100$ \\
S4 & $0-25-50-75-100$ \\
S5 & $0-20-40-60-80-100$ \\
S6 & $0-25-50-75-100$ \\
S7 & $0-20-40-60-80-100$ \\
Medical & Resource: (M1 + M2 + M3) / 3 = M \\
M1 & $0-25-50-75-100$ \\
M2 & $0-25-50-75-100$ \\
M3 & $0-25-50-75-100$ \\
\hline
\end{tabular}

psychologists performed, separately, an initial translation from the English language. The translated versions were then discussed and adjusted to obtain consensus and close equivalence to the original version. The text was then back translated from Italian into English by a bilingual person with a professional academic level of Italian and English and by a native English speaker. The original and back-translated English versions were compared by the two translators and, if discrepancies were found, the new version was adjusted to optimise the conceptual overlap.

\section{Study validation}

In the second phase of this study, we enrolled 54 patients affected by CSOM presenting to our clinic between November 2014 and November 2015 to evaluate the validity of the CES-I questionnaire and compare the results to those obtained with the Italian validated SF-36 survey. Diagnosis of CSOM was performed with medical history, 
Table III. Italian version of Chronic Ear survey (CES-I).

\begin{tabular}{|c|c|}
\hline \multicolumn{2}{|c|}{ Limitazione delle attività } \\
\hline \multirow[t]{2}{*}{ A1 } & A causa della malattia dell'orecchio, non può nuotare o fare la doccia senza proteggerlo. \\
\hline & $\square$ sicuramente vero $\quad \square$ vero $\quad \square$ non so $\quad \square$ falso $\quad \square$ sicuramente falso \\
\hline \multirow[t]{2}{*}{ A2 } & In questo momento quanto è grave dover tenere l'acqua lontano dall'orecchio? \\
\hline & $\square$ molto grave $\square$ grave $\square$ moderato $\square$ medio $\square$ lieve $\square$ nullo \\
\hline \multirow[t]{2}{*}{ A3 } & Nelle ultime 4 settimane la malattia dell'orecchio ha condizionato le sue attività in famiglia o con gli amici? \\
\hline & $\square$ sempre $\square$ molto spesso $\square$ una buona parte del tempo $\square$ talvolta $\square$ per un breve periodo $\square$ mai \\
\hline \multicolumn{2}{|r|}{ Sintomi } \\
\hline \multirow[t]{2}{*}{ S1 } & Ora, la perdita di udito è: \\
\hline & $\square$ molto grave $\square$ grave $\square$ moderata $\square$ media $\square$ lieve $\square$ nulla \\
\hline \multirow[t]{2}{*}{ S2 } & Ora, la secrezione dell'orecchio è: \\
\hline & 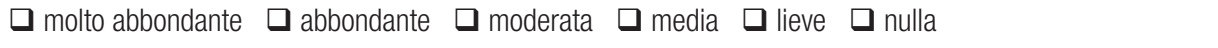 \\
\hline \multirow[t]{2}{*}{ S3 } & Ora, il dolore dell'orecchio è: \\
\hline & $\square$ molto grave $\square$ grave $\square$ moderato $\square$ medio $\quad \square$ lieve nullo \\
\hline \multirow[t]{2}{*}{ S4 } & L'odore dell'orecchio la preoccupa molto e/o preoccupa gli altri: \\
\hline & $\square$ sicuramente vero $\square$ vero $\square$ non so $\square$ falso $\square$ sicuramente falso \\
\hline \multirow[t]{2}{*}{ S5 } & La perdita di udito la preoccupa: \\
\hline & $\square$ sempre $\square$ molto spesso $\square$ una buona parte del tempo $\square$ talvolta $\square$ per un breve periodo $\square$ mai \\
\hline \multirow[t]{2}{*}{ S6 } & Negli ultimi 6 mesi quante volte l'orecchio ha prodotto pus: \\
\hline & $\square$ costantemente $\square 50$ più volte ma non costantemente $\square$ 3-4 volte $\square$ 1-2 volte $\square$ mai \\
\hline \multirow[t]{2}{*}{ S7 } & L'odore dell'orecchio la preoccupa e/o preoccupa gli altri: \\
\hline & 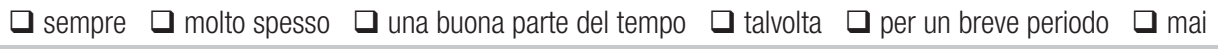 \\
\hline \multicolumn{2}{|r|}{ Interventi medici } \\
\hline \multirow[t]{2}{*}{ M1 } & Negli ultimi 6 mesi, quante volte è stato visitato dal suo medico per l'orecchio: \\
\hline & $\square$ più di 6 volte $\square$ 5-6 volte $\square$ 3-4 volte $\square 1-2$ volte $\square$ nessuna \\
\hline \multirow[t]{2}{*}{ M2 } & Negli ultimi 6 mesi, quante volte ha usato antibiotici orali per curare l'infezione dell'orecchio: \\
\hline & $\square$ più di 6 volte $\square 5$-6 volte $\square$ 3-4 volte $\square 1-2$ volte $\square$ nessuna \\
\hline \multirow[t]{2}{*}{ M3 } & Negli ultimi 6 mesi quante volte sono stati necessari periodi di cura con gocce auricolari? \\
\hline & $\square$ più di 6 volte $\square 5-6$ volte $\square$ 3-4 volte $\square 1$-2 volte $\square$ nessuna \\
\hline
\end{tabular}

general ENT examination (including micro-otoscopy), pure tone audiometry (PTA) and high resolution computerised tomography (CT) of temporal bone. Further data (age, gender, unilateral or bilateral disease) were collected. After obtaining written consent, the CES-I and SF-36 forms were administered to all patients.

\section{Statistical analysis}

Collected data were analysed statistically. Measures of central tendency (mean and median) as well as dispersion measures (standard deviation, SD; range: minimum maximum) were calculated. Test-retest reliability of the CES-I was determined by the intraclass correlation coefficient (ICC). A cross-sectional design was used to examine the internal consistency (Cronbach's alpha) and concurrent validity (Pearson's product moment correlation). Pearson correlation coefficient between the total score and single subscales of CES and the 8 scales of the SF-36 was used to examine the correlation between the CES-I and SF36. Physical composite score (PCS) and mental composite score (MCS) were calculated as summary criteria for the HRQoL. Statistical significance was set at $\mathrm{p}<0.05$. Statistical analysis was carried out using SPSS 22.0.

\section{Results}

54 patients were enrolled in the study, $26(48.1 \%)$ were females and $28(51.9 \%)$ males, with a median age of 42 (range 24-61) years. Bilateral CSOM was diagnosed in $18 \%$ of subjects.

In our sample, the CES-I presented a median value for activity restriction, symptoms and medical resources of 8, 22.5 and 9, respectively. The total score had a median value of 38.5 (range 14-53). The median PCS and MCS scores of SF-36 were 50.3 and 47.5, respectively, which are close to the median values for the Italian population $(\mathrm{PCS}=53.3$ and $\mathrm{MCS}=49.3$ )

The validity analysis of the CES-I questionnaire was strongly supported by our statistical analysis: Cronbach's 
Table IV. Characteristics of the patients according to the CES-I and SF-36 questionnaires.

\begin{tabular}{lccc} 
Variable & Mean & Median & SD, Range (min-max) \\
Chronic Ear Survey - I (CES-I) & & & $3.17(1-13)$ \\
$\quad$ Activity restriction sum & 8.04 & 8.00 & $4.75(11-31)$ \\
Symptoms sum & 22.31 & 22.50 & $2.52(0-12)$ \\
$\quad$ Medical resources sum & 8.70 & 9.00 & $7.02(14-53)$ \\
$\quad$ Total sum & 39.06 & 38.50 & $8.55(27.14-64.08)$ \\
Short Form 36 (SF-36) & & & $10.16(20.22-60.53)$ \\
$\quad$ Physical composite score (PCS) & 49.28 & 50.35 & 47.57 \\
$\quad$ Mental composite score (MCS) & 45.54 & & \\
\hline
\end{tabular}

alpha was 0.737 , while the intraclass correlation coefficient (ICC), measured through mixed effects, was 0.737 (95\% CI: $0.600-0.835, \mathrm{p}<0.001)$ for average measures and 0.412 (95\% CI: $0.273-0.559, \mathrm{p}<0.001)$ for individual measures.

Moreover, correlation analysis between the CES-I and SF-36 scores (the 8 areas and the two composite scores, PCS and MCS) was performed: a significant correlation was found between AR sum and the physical function (PF) score $(r=0.282, p=0.039)$, between $M R$ sum and role emotional score $(r=-0.303, p=0.026)$, and between the MR sum and the MCS score $(r=-0.273, p=0.045)$

\section{Discussion}

Over the last decade, there has been growing interest in developing instruments to define surgical and nonsurgical outcomes from a patient's perspective. Patient-reported outcome measures (PROMs) currently play a significant

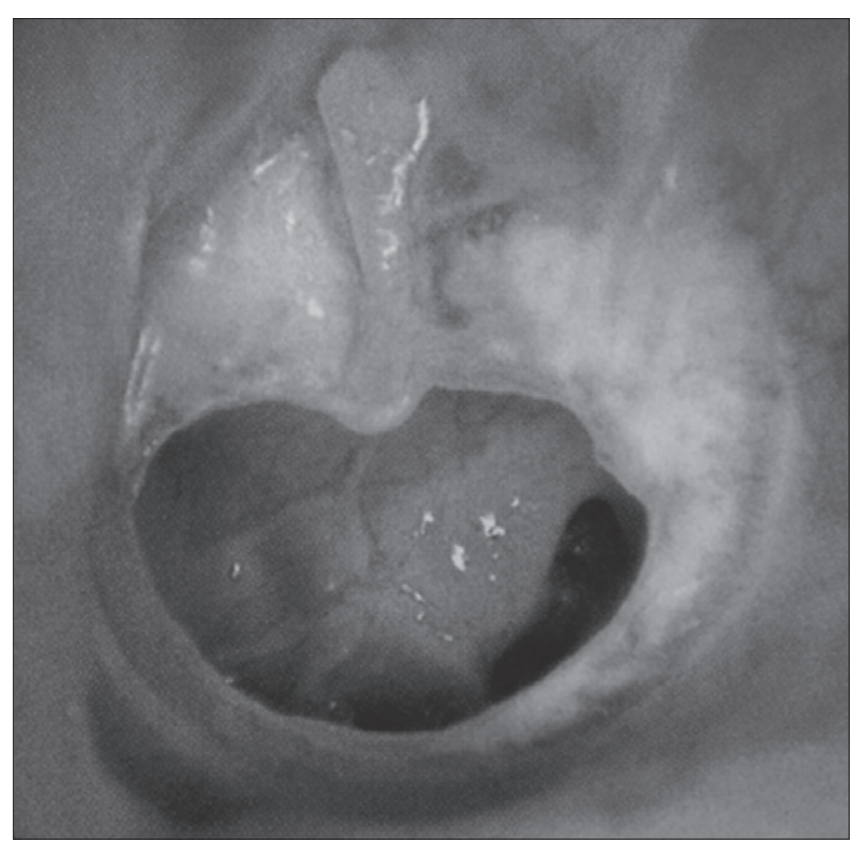

Fig. 1. Otoscopic image of CSOM with central perforation of the tympanic membrane. role in the assessment of outcome for reflective practice, audit and research. These PROMs consist of different methods of data collection such as tests, behavioural observations, content analysis, interviews, questionnaires, physiological and neuropsychological measures, inventories and personality scales measuring attitudes.

The questionnaire is a very effective tool for data collection in terms of reliability and validity of the data. The word validation is often used indiscriminately to define a process of survey evaluation, whereas certain tests, such as evaluating internal consistency, are not truly tests of validity. The evaluation of survey instruments comes under the branch of survey research known as psychometrics. Generally, this process can be split into the evaluation of reliability and validity. Reliability takes the form of features such as testretest reliability, alternate-form reliability, internal consistency, interobserver reliability and intraobserver reliability. Validation, on the other hand, takes the form of content validity, criterion validity and construct validity ${ }^{19}$.

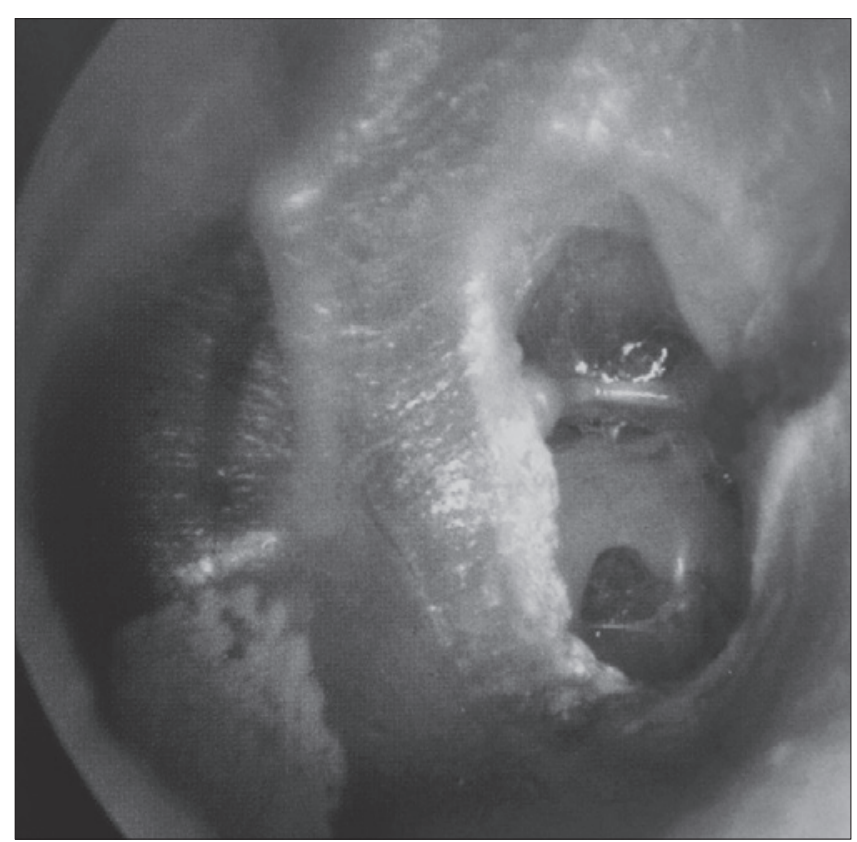

Fig. 2. Otoscopic image of CSOM with marginal perforation of the tympanic membrane. 
Questionnaire validation is not a single exercise, and to achieve some forms of validation, such as construct validation, the process involves gathering a group of different types of data over a multitude of settings and populations over a number of years.

A number of studies have investigated association between social aspects and health. More information on social aspects among people with chronic illness could increase our understanding of the processes involved in the wide variety of situations ${ }^{20}$. Using questionnaires in different languages gives us the opportunity to study and compare different populations and cultures, gather information from various health systems and understand the importance of a disease and its treatment adequacy.

So far, there has been no Italian instrument available to assess QoL for patients with CSOM; although an Italian version of the SF-36 survey was proposed in 2000, it has proven not to be sensitive enough for this condition. In this study, we demonstrate the CES-I to be a valid, disease-specific health measure that can be used to evaluate adult patients with CSOM among the Italian speaking population.

In our validation process, we found a Cronbach's alpha of 0.737 , demonstrating very good reliability of this tool in the Italian setting. Correlation of the CES-I with the validated Italian SF-36 general health measure was used as a test of convergent validity: when comparing our results to the findings of Nadol et al., the CES total survey score had significant correlation with several subscales of the SF36: a significant correlation was found between AR sum and PF score, between MR sum and role emotional score, and between MR sum and MCS score.

In the AR subscale, there are questions about the restriction of social activity by hearing loss, and this correlation means that there may be an important influence of QoL in patients who experience improvements in hearing.

In our results, the MR and AR subscale scores are lower than those on other subscales. This may be attributable to the easy accessibility of medical resources and suggests that patients included in this study were adapted to their status, including their hearing loss, and were more cautious in their daily life. Neither the CES nor the CCES (as demonstrated in the Chinese validation study) were significantly correlated with PTA: this is a finding that should be further analysed in future studies. The CES questionnaire, and consequently the CEI-I in the Italian population, appeared to be a valid, reliable and sensitive disease-specific health measure that adds another dimension to our understanding of the impact of the disease on patients with CSOM.

\section{Conclusions}

CSOM is a common disease that has a significant health impact on general population and is far from being eradicated. The use of tools that are able to evaluate QoL in pa-

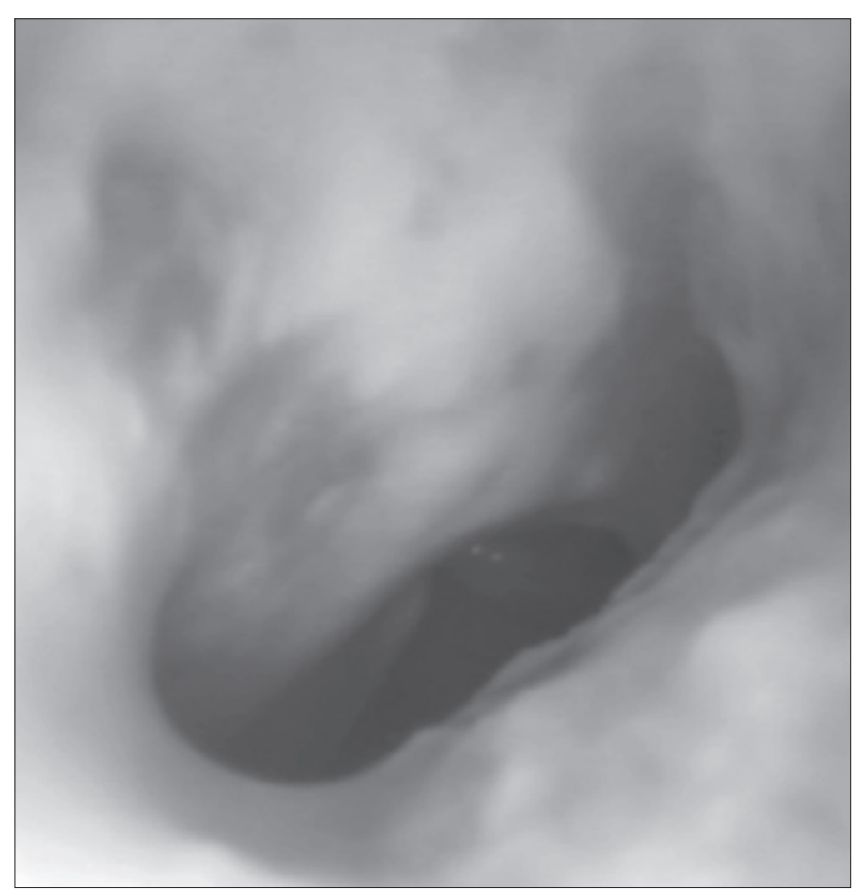

Fig. 3. Otoscopic image of "active" CSOM with anterior perforation of the tympanic membrane.

tients affected by this disease is useful for greater awareness of the results of surgical and medical treatments. The CES questionnaire was a valid tool to assess QoL in CSOM patients; however, the absence of an Italian version of this tool makes it difficult to use it among Italian speaking patients. Based on the results of our study, the CES-I questionnaire appears to be a reliable and valid instrument for the investigation of health status among Italian speaking patients with CSOM.

\section{References}

1 Ralli G. Chronic suppurative otitis media. Edizioni Minerva Medica 2004;1:1-2

2 Demir UL, Akyildiz MY, Alpay M. The factors which affect disease-specific quality of life in patients with chronic otitis media. Int Adv Otol 2012;8:371-8.

3 Sheppard A, Hayes SH, Chen GD, Ralli M, Salvi R. Review of salicylate-induced hearing loss, neurotoxicity, tinnitus and neuropathophysiology. Acta Otorhinolaryngol Ital 2014;34:79-93.

4 Vartiainen E. Changes in the clinical presentation of chronic otitis media from the 1970s to the 1990s. J Laryngol Otol 1998;112:1034-7.

5 Armstrong D, Caldwell D. Origins of the concept of quality of life in health care: a rhetorical solution to a political problem. Social Theory \& Health 2004;2:361-71.

6 World Health Organization (WHO). International classification of impairments, disabilities and handicaps: a manual of classification relating to the consequences of disease. Proceedings of World Health Organization 1980 Geneva.

7 Quality of life / CDC. Atlanta GA: National Center for 
Chronic Disease Prevention and Health Promotion HealthRelated Quality of Life; 2013.

8 Ware JE, Kosinski M. SF-36 physical and mental health summary scales: a manual for users of version 1. Second Edition. Quality Metric Incorporated; Lincoln, RI: 2001.

9 Ware JE, Sherbourne CD. The MOS 36-Item Short-Form Health Survey (SF-36). I. Conceptual framework and item selection. Med Care. 1992;30:473-483.

10 Apolone G, Mosconi P. The Italian SF-36 Health Survey: translation, validation and norming. $\mathrm{J}$ Clin Epidemiol 1998;51:1025-36.

11 Healthy People 2020 Foundation Health Measure Report Health-Related Quality of Life and Well-Being. Washington: Office of Disease Prevention and Health Promotion 2010.

12 Wang PC, Nadol JB, Merchant S, et al. Validation of outcomes survey for adults with chronic suppurative otitis media. Ann Otol Rhinol Laryngol 2000;109:249-54.

13 Nadol BJ, Staecker H, Gliklich R. Outcomes assessment for chronic otitis media: the chronic ear survey. Laryngoscope. 2000;110(3):32-5.
14 Wang PC, Chu CC, Liang SC, et al. Validation assessment of the Chinese-version Chronic Ear Survey: a comparison between data from English and Chinese versions. Ann Otol Rhinol Laryngol 2003;112:85-90.

15 Byun JY, Cho YS, Chu H, et al. Standardization for a Korean version of chronic ear survey: translation and verification of validity and reliability. Korean J Otorhinolaryngol Head Neck Surg 2011;54:755-60.

16 Dunham P.J. Experimental psycology: theory and practice. New York: Harper and Row; 1977

17 Pedon A, Gnisci A. Metodologia della ricerca psicologica. Bologna: Il Mulino 2004.

18 Sartorius N, Kuyyken W. Translation of health status instruments. Berlin: Springer-Verlag; 1994

19 Streiner DL, Norman GR. Health measurement scales: a practical guide to their development and use. Fifth Edition. Oxford: Oxford University Press 2003.

20 Dibb B, Yardley L. Factors important for the measurement of social comparison in chronic illness: a mixed-methods study. Chronic Illn 2006;2:219-30.

Received: May 21, 2016 - Accepted: July 27, 2016

Address for correspondence: Giovanni Ralli, Institute of Otorhinolaryngology, Policlinico Umberto I, viale del Policlinico, 00161 Rome, Italy. Tel. +39 06 44236080. E-mail: gralli@libero.it 